ORIGIAAL PAPERS

報 文

( 7 )

\title{
製塩用エンタルピー・組成線図の作成*
}

楠一浩 一 郎**

二成分系の熱収支計算においいてエンタルピー・組成線 图の有用なことは広く知られ，Perry の Handbook や Haugen らへの著書などにも述へてある。海水淟縮によ る製塩の熱計算にるこの種の線図が利用できると都合が よいので，その作成を企てた。

まず海水を二成分系の形で表わし，系の状態を調へな ければならぬ。

多くの研究によると海水中に溶存している塩類相互の 割合は，地球上どこでる一定とみなすことができ，Tab. 1 に示した值をむつ。そこでこの海水中の塩分を総括し て全塩分 Sという一成分と考党ると, 海水は全塩分 $\mathrm{S}$ と 水との二成分からなるとすることができる。のように 定義すると，この二成分采の組成は析出塩が存在すると き, $\mathrm{S}$ の重量パーセントは

\section{$\frac{\text { 溶存塩重量十析出塩重量 }}{\text { 溶 液 重 }} \times 100$}

で表わされる。したがって海水濃縮系のエンタルピー。 組成線図を，単独塩水溶液のそれと同様の方法で作成可 能となる。

そこで海水を大気圧下で濃縮した際の溶存塩，析出塩

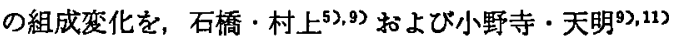
の実験と, J. D'Ans ${ }^{13,92}$ らの海洋塩の溶解平衡の研究 を参照して各温度で決定し，これを元として全塩分 S$\mathrm{H}_{2} \mathrm{O}$ 系の各組成でのエンタルピー $H$ を次式で計算した。

$$
H=H_{l}+H_{0}
$$

ここで全析出塩のエンタルピー $H$, は各析出塩のエン タルピーの和として，また溶夜のエンタルピー $H_{1}$ は後 にのへるように各成分塩の単独水溶液のエンタルピーと 溶液中塩類のモル数から, 加成的に求めた。

Fig. 1 が作成したエンタルビー・組成腺図で $0^{\circ} \mathrm{C}$ 大 気压下の水の $1 \mathrm{~kg}$ と全塩分 $\mathrm{S} 1 \mathrm{~kg}$ をそれぞれ基集と している。図中×点绀復塩の析出開始点を示し, 緃の曲 線から析出食塩量が分る。この図にはまた，大気圧下沸 滕しつつある系に共存水蒸気を加えた気・液・固相共存 系の等温線と, 種々の王力下の沸点に括ける液・固相系 のエンタルピーを示す等圧沸点線をす含んでいる。以下 に計算・作四法の大要と使用例を述へる。

\footnotetext{
- 昭和 32 年 7 月 8 日受理
}

* 九州大学工学部底用化学科
1. 海水組成

製塩用図表集》から専売公社にならって Fleming ${ }^{23,9)}$ の决定に上る値を採り Table 1 に示した。これによる と海水中の全塩分 Sは $3.425 \%$ である。

\section{2. 海水の恒温 (大気圧) 濃縮による組成变化}

製監図表集に Usiglio らの実験結果が出ているが，実 験技術に困難な点が多いので，相当誤差を含をと思われ る。ここでは $40^{\circ} \mathrm{C}$ における石橋ら ${ }^{52,9)}$ の実験と, 沸点 蒸発による小野寺ら92,11) の結果を使用した。Fig. 2 は

Table 1

Principal Composition of Sea Water

\begin{tabular}{|c|c|c|c|}
\hline Salt & $\begin{array}{l}\text { Grams per } \\
\text { kg of Sea } \\
\text { Water }\end{array}$ & $\begin{array}{l}\text { Per Cent by } \\
\text { Weight of } \\
\text { Total Salts }\end{array}$ & $\begin{array}{l}\text { Moles for } \\
34.25 \mathrm{~g} \text { of } \\
\text { Total Salt }\end{array}$ \\
\hline $\mathrm{NaCl}$ & 26.69 & 77.93 & 0.4567 \\
\hline $\mathrm{MgCl}_{2}$ & 3.28 & 9.59 & 0.0344 \\
\hline $\mathrm{MgSO}_{4}$ & 2.10 & 6.12 & 0.0174 \\
\hline $\mathrm{CaSO}_{4}$ & 1.38 & 4.03 & 0.0101 \\
\hline $\mathbf{K C l}$ & 0.72 & 2.11 & 0.0098 \\
\hline $\mathrm{MgBr}_{2}$ & 0.08 & 0.22 & 0.0004 \\
\hline \multirow{3}{*}{$\begin{array}{l}\text { Total Salts } \\
\text { Difference by } \\
\text { water }\end{array}$} & 34.25 & 100.00 & \\
\hline & 965.75 & & \\
\hline & 1000.00 & & \\
\hline
\end{tabular}

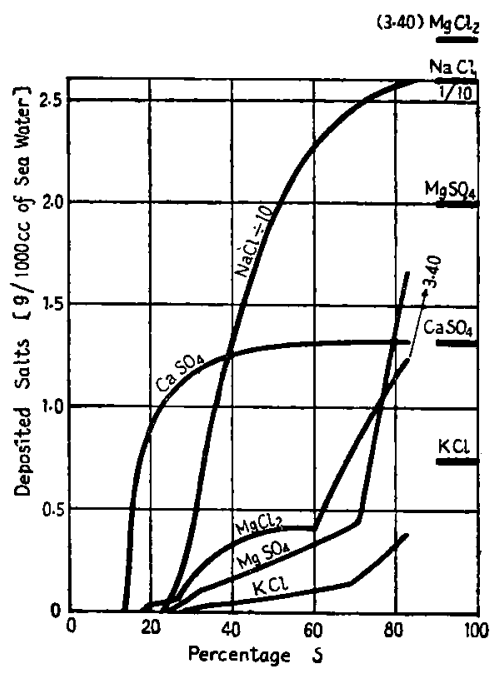

Fig. 2 Salts deposited by concentration of sea water at $40^{\circ} \mathrm{C}$ 


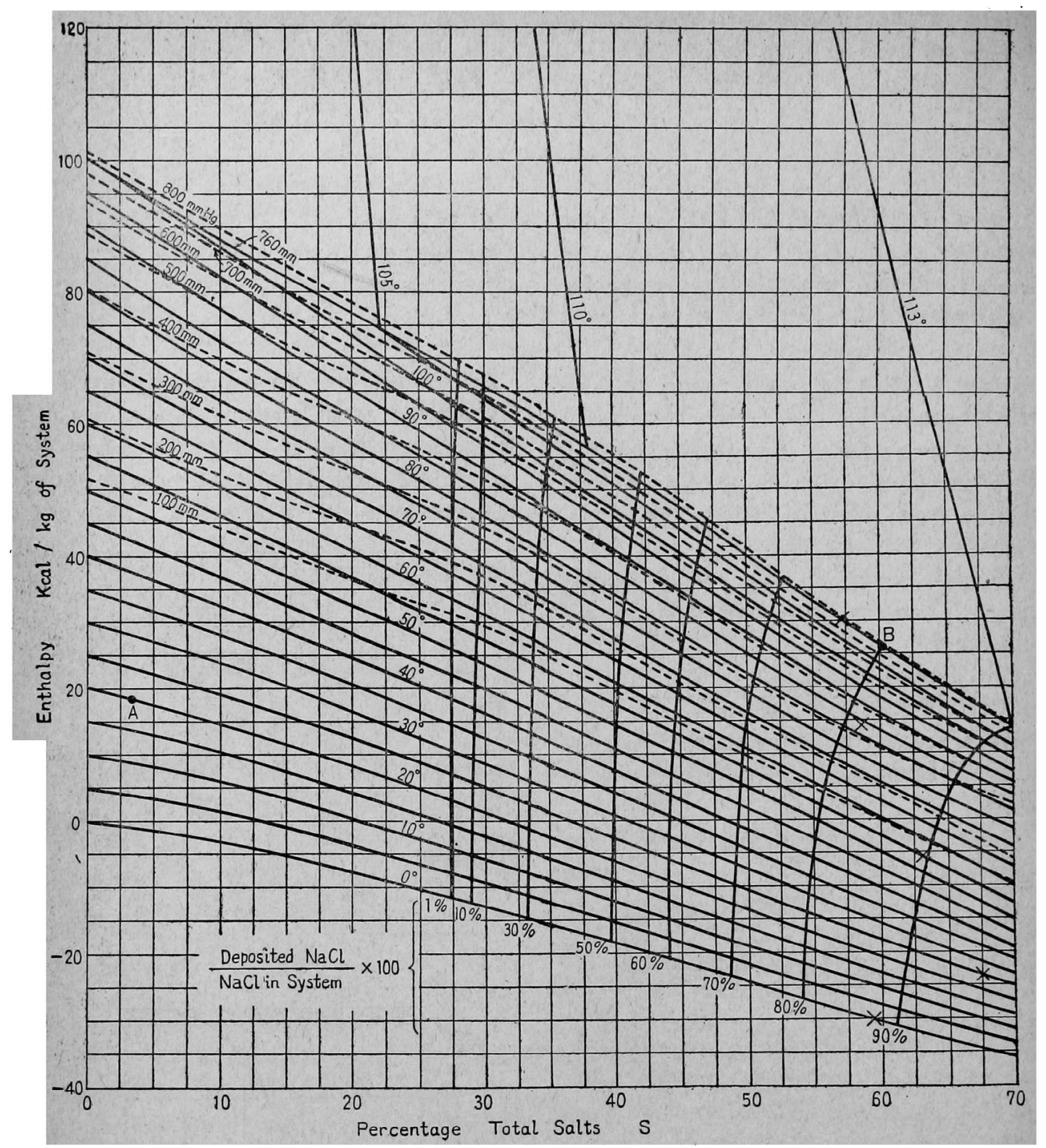

Fig. 1 Enthalpy-composition diagram for total salts $\mathrm{S}-\mathrm{H}_{2} \mathrm{O}$ system

石橋らの結果である。一方 J. D'Ans ${ }^{1,92}$ らの海洋塩の 溶解平衡 ( $\mathrm{K}_{2}-\mathrm{Mg}-\mathrm{Na}_{2}-\mathrm{Cl}_{2}-\mathrm{SO}_{4}-\mathrm{H}_{2} \mathrm{O}$ 系, $\mathrm{NaCl}$ 館和) の研究によれば，次節でのべるよー5に，全塩分が約 57\% の組成になって始めて $\mathrm{Mg}, \mathrm{SO}_{4}, \mathrm{~K}$ などを含んだ塩が， 種ふの複塩として沈澱してくる(この研究には $\mathrm{CaSO}_{4}$ は含まれていない。Fig. 1 の点は，D’Ans の結果に 上る各温度における複塩析出開始時の組成である。した がって Fig. 2 に示した濃鏥実験では, $\mathrm{MgCl}_{2}, \mathrm{MgSO}_{4}$, $\mathrm{KCl}$ なとが $\mathrm{CaSO}_{4}, \mathrm{NaCl}$ の析出ととすに少量だが早
くから出てきたが,この報文では約 $57 \%$ S の組成まて は, 寸なわらメ点までは, $\mathrm{CaSO}_{4}, \mathrm{NaCl}$ 以外の塩は析 出しないこととした。

こうして小野寺らと石橋らのデータで, $40^{\circ} \mathrm{C}$ と沸点 飞指りる $\mathrm{Mg}$ 塩析出前の濃縮による，組成变化を決定し た。他の温度で性利用できるデータがないので，以上の 二つの結果から比例配分によって計算した。ただ食塩の 水汇対する溶解度は, $0^{\circ} \mathrm{C}$ から $40^{\circ} \mathrm{C}$ の間で $1.5 \%$ 增す にすきぬので, 海水の場合す $40^{\circ} \mathrm{C}$ 以下での食塩の溶存 
量は $40^{\circ} \mathrm{C}$ の值をそのまま使用した。 $\mathrm{CaSO}_{4}$ の海水中の 塎解度は，沸点でる $40^{\circ} \mathrm{C}$ でもほとんど変らぬことが石 檑々小野寺の結果からわかる。これの析出塩は水和物で あるが, $80^{\circ} \mathrm{C}$ 以上では $1 / 2$ 水程, $80^{\circ} \mathrm{C}$ 以下では 2 水塩 とした。

\section{3. $\mathbf{M g}$ 塩析出組成付近における系の変化}

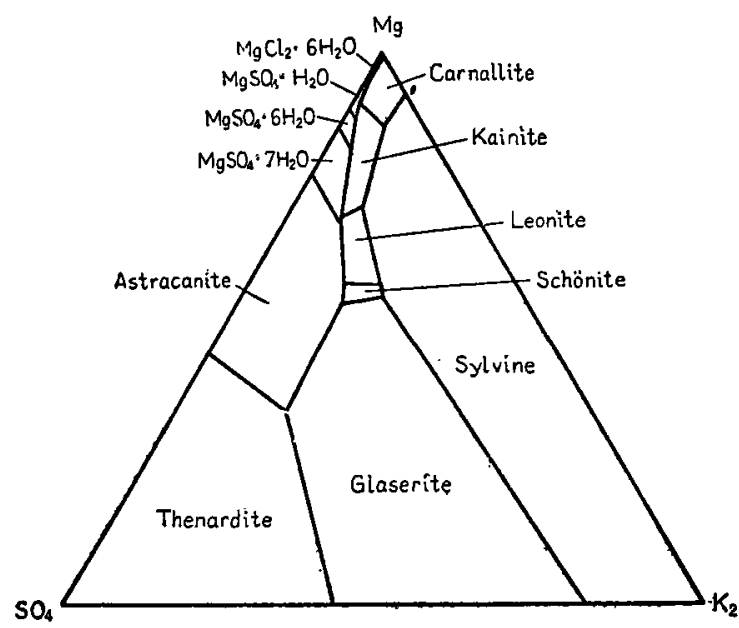

Fig. 3 Equilibrium diagram for the system $\mathrm{Na}-$ $\mathrm{K}-\mathrm{Mg}-\mathrm{Cl}-\mathrm{SO}_{4}-\mathrm{H}_{2} \mathrm{O}$ saturated with $\mathrm{NaCl}$ at $25^{\circ} \mathrm{C}$

Table 2 Initial Double Salts Deposit by Concentration of Sea Water at Several Temperatures

\begin{tabular}{rcll}
$\ell^{\circ} \mathrm{C}$ & $\begin{array}{l}\text { Weight Per Cent } \\
\text { of Total Salts }\end{array}$ & $\mathrm{S} \mathrm{a} 1 \mathrm{t}$ \\
\hdashline 0 & 59.4 & Heptahydrate & $\mathrm{MgSO}_{4} \cdot 7 \mathrm{H}_{2} \mathrm{O}$ \\
25 & 67.5 & Astracanite & $\mathrm{Na}_{2} \mathrm{SO}_{4} \cdot \mathrm{MgSO}_{4} \cdot 4 \mathrm{H}_{2} \mathrm{O}$ \\
55 & 63.0 & Löweite & $2 \mathrm{Na}_{2} \mathrm{SO}_{4} \cdot 2 \mathrm{MgSO}_{4} \cdot 4 \mathrm{H}_{2} \mathrm{O}$ \\
83 & 58.6 & Löweite & $"$ \\
110 & 57.2 & Vanthoffite & $3 \mathrm{Na}_{2} \mathrm{SO}_{4} \cdot \mathrm{MgSO}_{4}$ \\
\hline
\end{tabular}

$\mathrm{Mg}$ 塩が析出し始めるとき，Fig. 2 から明らかなよる にCaSO、はほとんど析出してしまっているし， $\mathrm{NaCl} は$ 飽和にある。したがって系の状態は前述の D'Ans の研 究と同じとみなせるので，濃縮実験より精度が高いD' Ans の結果を利用した。

同氏による $0^{\circ}, 25^{\circ}, 55^{\circ}, 83^{\circ} \mathrm{C}$ の海洋程溶解平衔の

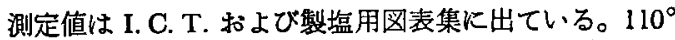
Cの值は未確定だが, D’Ans の原著からえて利用 した。これらの結果は定温定圧では Fig. 3 に例 示したよ5に $\mathrm{Mg}, \mathrm{K}_{2}, \mathrm{SO}_{4}$ の三成分を考えた三 角柱座標で示される。この図についての㘠計算と， 物質収支から，海水濃縮による複塩の析出と系組 成の関係が明らかにできる。海水涉縮で最初に出 てくる複塩をこの計算で求めTable 2 に示した。 この種の計算についてては大幸勇吉 ${ }^{123}$ の著書に詳し、 く，岡俊平10〉の総説もある。

$0^{\circ}, 25^{\circ}, 55^{\circ}, 83^{\circ}$ ，沸点に批忛全塩分 S $70 \%$ な゙恒温港縮による系の組成変化を以上の 結果之前節で述べた実験值からの比例計算で決定 し, エンタルピー計算の基礎とした。 $55^{\circ} \mathrm{C}$ に捅 ける組成变化を Table 3 に例示した。

\section{4. エンタルピーの計算}

（a）基 準 $0^{\circ} \mathrm{C}$ 大気圧下の水々全塩分 $\mathrm{s}$ の エンタルピーをそれぞれ $0 \mathrm{cal} / \mathrm{g}$ とた。 Sにつ いては，Sを構成している各塩の $0^{\circ} \mathrm{C}$ に淤けるエ

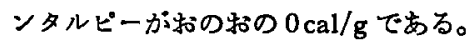

（b）全塩分-水系のエンタルピー計算法 (1) 式により液相と固相に分けて計算した。全析出塩 のエンタルピー $H_{\mathrm{a}}$ は各析出塩のエンタルピーの 和としてえられる。

$$
\begin{aligned}
& \text { 溶液のェンタルピー } H_{1} \text { は一般に } \\
& \qquad \begin{aligned}
H_{l} & =n_{1} \overline{\mathrm{B}}_{1}+n_{2} \overline{\mathrm{H}}_{2}+\cdots \cdots \\
& =n_{1} \mathrm{~B}_{1}{ }^{0}+n_{2} \mathrm{H}_{2}{ }^{0}+\cdots \cdots+\Delta H
\end{aligned}
\end{aligned}
$$

\begin{tabular}{|c|c|c|c|c|}
\hline \multirow[b]{2}{*}{$\mathrm{NaCl}$} & \multicolumn{3}{|c|}{ Salts in Solution [g] } & \multirow[b]{2}{*}{$\mathrm{CaSO}_{4}$} \\
\hline & $\mathrm{MgCl}_{2}$ & $\mathrm{MgSO}_{4}$ & $\mathrm{KCl}$ & \\
\hline $\begin{array}{c}26.7 \\
" \prime \\
" ~\end{array}$ & $\begin{array}{c}3.28 \\
" \\
" 1 \\
"\end{array}$ & $\begin{array}{c}2.10 \\
" \\
" \\
"\end{array}$ & $\begin{array}{c}0.72 \\
" 1 \\
"\end{array}$ & $\begin{array}{l}1.38 \\
1.38 \\
1.04 \\
0.58\end{array}$ \\
\hline $\begin{array}{c}" \prime \prime \\
22.3 \\
16.7\end{array}$ & $\begin{array}{l}" \prime \\
" \prime \\
" ~\end{array}$ & $\begin{array}{l}" \prime \\
" \prime \\
" \prime\end{array}$ & $\begin{array}{l}" 1 \\
" 1 \\
" 1\end{array}$ & $\begin{array}{l}0.34 \\
0.25 \\
0.18 \\
0.13\end{array}$ \\
\hline $\begin{array}{l}10.0 \\
4.06 \\
2.16 \\
0.662\end{array}$ & $\begin{array}{c}n \\
n \\
3.66\end{array}$ & $\begin{array}{c}" \prime \\
" \prime \\
1.13\end{array}$ & $\begin{array}{l}" \prime \\
" \prime \\
" \prime\end{array}$ & $\begin{array}{l}0.08 \\
0.04 \\
0 \\
0\end{array}$ \\
\hline
\end{tabular}

Table 3 Composition Variation of Sea Water by Isothermal Concentration at $55^{\circ} \mathrm{C}$

\begin{tabular}{rcc} 
No. & $\begin{array}{c}\text { Weight Per Cent } \\
\text { of Total Salts, S }\end{array}$ & $\begin{array}{c}\text { Total Weight } \\
\text { of System [g] }\end{array}$ \\
\hline 1 & 3.43 & 1000 \\
\hline 2 & 12.6 & 272 \\
3 & 15.5 & 222 \\
4 & 19.1 & 180 \\
5 & 23.6 & 145 \\
6 & 27.1 & 126 \\
7 & 30.8 & 111 \\
8 & 36.1 & 95.0 \\
9 & 45.7 & 75.0 \\
10 & 58.7 & 58.4 \\
11 & 65.0 & 52.7 \\
12 & 72.6 & 47.2
\end{tabular}

\begin{tabular}{lcc}
\multicolumn{3}{c}{ Deposits [g] } \\
$\mathrm{NaCl}$ & CaSO $_{4} \mathbf{2} \mathrm{H}_{2} \mathrm{O}$ & Löweit \\
\hline 0 & 0 & 0 \\
0 & 0 & 0 \\
0 & 0.43 & 0 \\
0 & 0.40 & 0 \\
0 & 1.31 & 0 \\
0 & 1.42 & 0 \\
4.39 & 1.51 & 0 \\
9.99 & 1.58 & 0 \\
16.7 & 1.65 & 0 \\
22.6 & 1.70 & 0 \\
24.5 & 1.75 & 0 \\
26.0 & 1.75 & 1.238
\end{tabular}


で表わされる。しかしこの系では偏微分エンタルピーる 混合溶解熱る分らぬので近似許算を行った。すなわら， この混合溶液の全モラリティ $\{$ と同じモラリティの各単 独塩水溶液のエンタルピーを, 泥合溶液中の各塩のモル 数沁心して加算して $H_{l}$ を求めた。

今溶液中の各塩のモル数を $n_{i}(i=1,2, \cdots 5)$, 全モラ リティを $m$, 各塩の単独水溶夜のモラリティ $m$ に打ける ×ンタルピーを $H_{i}$ (cal of solution/mole of solute) と すると

$$
H_{l}=n_{1} H_{1}+n_{2} H_{2}+\cdots \cdots
$$

Y. Y. Kaganovich ${ }^{6)}$ か $\mathrm{MgCl}_{2}$ 溶液中への $\mathrm{KCl}$ の溶 解熱を湘定しているので, 以上の近似計算をテストして みた。 Kaganovich によると $50^{\circ} \mathrm{C} て ゙ ~ c=0.58,1.45$, 2.11, $2.75\left(c=\right.$ moles $\left./ 1000 \mathrm{~g} \mathrm{H}_{2} \mathrm{O}\right)$ の $\mathrm{MgCl}_{2}$ 溶液比 $\mathrm{KCl} 0.266$ moles $/ 1000 \mathrm{~g} \mathrm{H}_{2} \mathrm{O}$ だけとかしたときの租 分溶解熱は，それそれ $\Delta H=3460 ， 3545 ， 3704,3761 \mathrm{cal} /$ mole $\mathrm{KCl}$ である。これを使って各組成の $\mathrm{KCl}-\mathrm{MgCl}_{2}$ 水溶液のエンタルピーを計算, 上述の近似法による值と 比較した。Table 4 はその結果であるが, 両者の差は 0.7\%以下であった。

（c）析出複塩のエンタルピー 析出複壏は Table 3 から分るように問題にしている組成範囲では系全重量 の $2 \%$ 程度であり, 溶液に比べるとそのェンタルピーは 小さいので, 近似として複塩としてではなく単なる硫酸

Table 4 Enthalpies of $\mathrm{KCl}-\mathrm{MgCl}_{2}$ Aqueous Solutions at $50^{\circ} \mathrm{C}[\mathrm{cal} / \mathrm{g}$ ]

$\begin{array}{lrrrr}\text { Molality of } \mathrm{MgCl}_{2} & 0.58 & 1.45 & 2.11 & 2.75 \\ \text { Enthalpy from Experiment } & 28.40 & -2.483 & -22.73 & -41.32 \\ \text { Enthalpy by Calculation } & 28.20 & -2.55 & -22.90 & -41.57\end{array}$

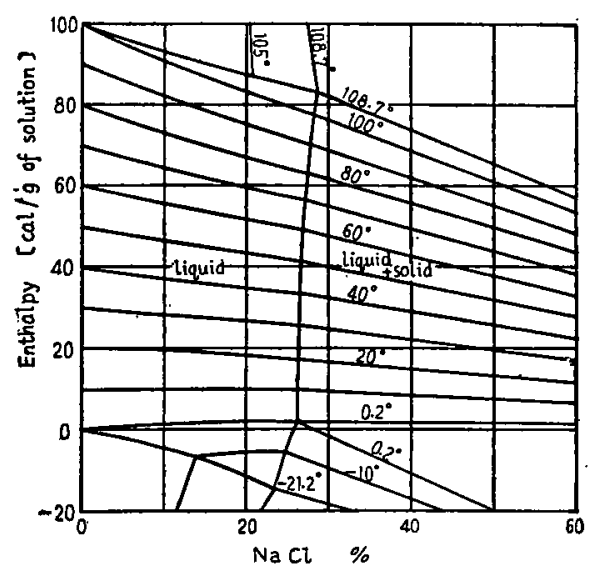

Fig. 4 Enthalpy-composition diagram for $\mathrm{NaCl}-\mathrm{H}_{2} \mathrm{O}$ system
塩としてそのエンタルピーを計算した。

(d) $\mathrm{NaCl}, \mathrm{MgCl}_{2}, \mathrm{MgSO}_{4}, \mathrm{KCl}, \mathrm{CaSO}_{4}$ の各蕇 独水溶液のエンタルピー （2）式の $H_{i}$ を求めるのに 必要なので, 各塩の単独水溶液のエンタルピー・沿度㷧 因を作成した。その作図法括よび食塩水溶液の図 (Fig. 4 に示した) については筆者》の報文がめる。他の系の 図 (Fig. 5,6)は, 必要なデータを化学便覽, Landolt の表, Rutskov ${ }^{13)}$ と Kaganovich ${ }^{72}$ の報文などから求め それぞれ作図した。 $\mathrm{MaCl}_{2}, \mathrm{KCl}$ の各水溶液については

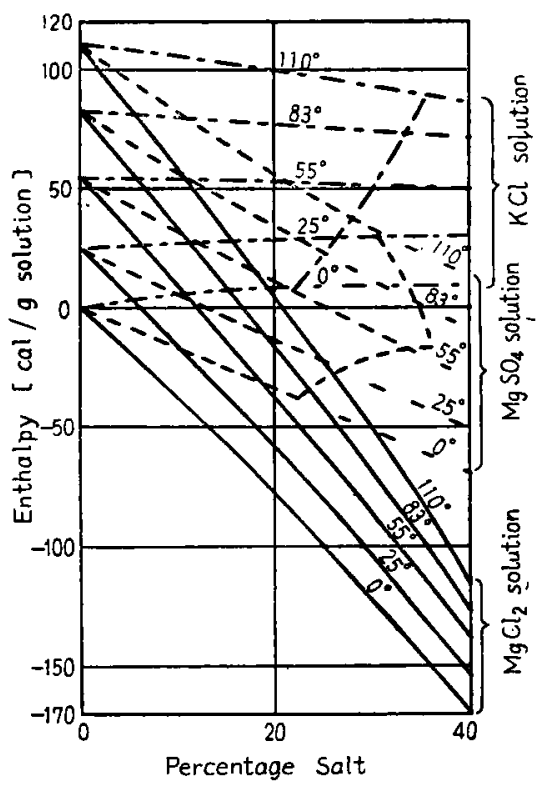

Fig. 5 Enthalpies of various sigle salt aqueous solutions

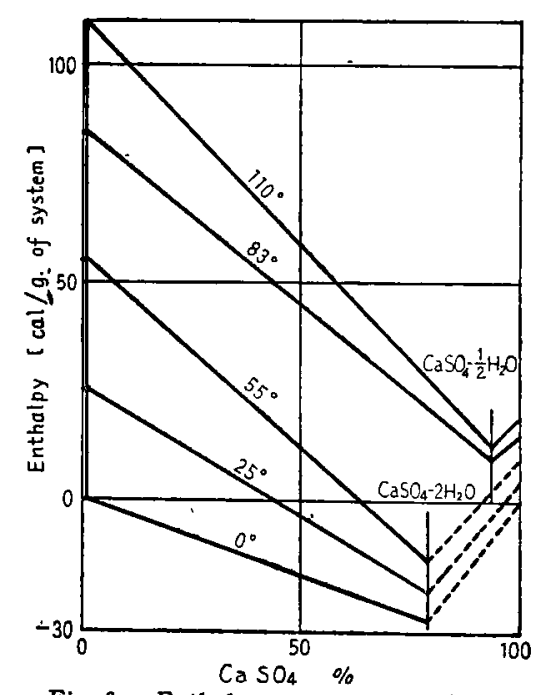

Fig. 6 Enthalpy-concentration diagram for $\mathrm{CaSO}_{4}-\mathrm{H}_{2} \mathrm{O}$ system 
等温線を溶解度曲線をこえて延畏し，必要な漫厚液のエ ンタルピーを便宜的に求め利用した。また $\mathrm{CaSO}_{4}$ は溶 解度がきわめて小さく，（2）式の $\mathrm{CaSO}_{4}$ 溶液について の $H_{5}$ 恃非常溥い溶夜以外では求められないので, 純 水のエンタルピーと $\mathrm{CaSO}_{4} \cdot 2 \mathrm{H}_{2} \mathrm{O}$ または $\mathrm{CaSO}_{4} \cdot \frac{1}{2} \mathrm{H}_{2} \mathrm{O}$ の溶解熱で代用した。

\section{5. 作 困}

$0^{\circ} ， 25^{\circ} ， 55^{\circ} ， 83^{\circ}$ ，沸点の各温度の海水采沉つて （b）で述べた計算を行い Fig. 1 の相当温度の等温線を 得，比例計算を行って他の温度についても作図した。

Fig. 1 亿は析出食塩の系中全食塩に対する割合る示し ている(図中縦の曲線)。また同図で，上方にのびる等温 楾は大気死下沸点に和ける気・液・固三相共存系のエン タルピーと組成を示している。この作図は普通の二成分 系と同様にして行った。

\section{6. 種々の王力下の系のエンタルピー}

海水濃縮時の蒸気圧の湘定は原 ${ }^{329}$ ，内田 ${ }^{92143}$, 芝915) らによって行われている。ただ测定には困難な点が多く 塩が析出している組成ではことに信頼度が少ない。筆者 は内田と艺のデータを使用した。

溶液のエンタルピーは压変化の影響をほとんと゚うけず 液相への影響は沸点变化たけである。Fig. 1 の破線は各 蒸気压下の沸点線で，その温度忙等温線で読放るした

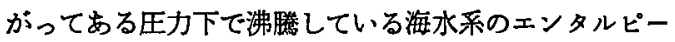
は，系の組成が分ると蒸気相を含む場合る，この図と蒸 気表から容易に求まる。

\section{7. $\mathrm{NaCl}-\mathrm{H}_{2} \mathrm{O}$ 系線図との比較}

Fig. 5 から明らかなように Mg 塩類水溶液のエンタル ピーは Fig. 4 の NaCl 溶液のエンタルピーに比して同 せ濃度 (\%) で著しく小さい。したがって海水の場合む 全塩分 $\mathrm{S}$ のパーセントがますにつれて $\mathrm{Mg}$ 塩の効果が大 きくなり，Fig. 1 と Fig. 4 の明瞭な相違を生じる。

[使用例] 常温の海水 $1 \mathrm{~kg}$ を大気圧下で加熱漲縮し て，その食塩を $80 \%$ 析出させるに要する熱量を計算して みよう。Fig. 1 で始めの海水はA点に相当し，濃縮した 液と析出塩のエンタルピーはB点に相当する。A点組成 はSが 3.43\%，B点では60\%であるから、蒸発した水 蒸気量は

$$
(1000-34.3)-34.3(0.40 / 0.60)=942.9[\mathrm{~g}]
$$

B点の温度は $112^{\circ} \mathrm{C}$ なので，海水の沸点 $100.2^{\circ} \mathrm{C}$ との 平均温度 $106^{\circ} \mathrm{C} て ゙$, 蒸発して䟴縮されたと仮定すると， この温度に㧊ける水蒸気のェンタルピーは蒸気表を利用
Lて

$$
641 \times 943=604,000[\mathrm{cal}]
$$

B点の液・固相エンタルピーは Fig. 1 から

$$
26.0(34.3 / 0.60)=1490[\mathrm{cal}]
$$

$\mathrm{A}$ 点のエンタルピーは $18.3[\mathrm{kcal} / \mathrm{kg}]$

したがって所要熱量は

$$
604,000+1,490-18,300=587,200 \text { [cal] }
$$

気相を含めた等温線が利用できると計算はさらに簡単 になる。これについては一般の二成分系のエンタルピー

・組成線図使用例を参照されたい。

作成した線図は明らかに簃密なるのではなく，濃縮時 の組成变化と濃厚溶液のエンタルピーおよび蒸気圧につ いては，さらに実験改良を必要とする。しかし実用には 充分と思标る。

終りにこの仕事を命ぜられ指導，助言をいただいた坂 井 渡教授に深く感謝する。

\section{Nomenclature}

$H$ : enthalpy

$\bar{B}^{0}$ : enthalpy of a pure component

$\Delta H$ : heat of mixing

$H_{i}$ : enthalpy of $i$ th single salt aqueous solution at molality $m$ [cal of solution/mole of solute]

$\overline{\mathbf{B}}_{i}$ : partial molal enthalpy of component $i$

$H_{l}$ : enthalpy of a liquid

$H_{8}$ : enthalpy of a solid

$i: 1,2, \cdots \cdots$ (subscript)

: respectively, $\mathrm{NaCl}, \mathrm{MgCl}_{2}, \mathrm{MgSO}_{4}$, $\mathrm{KCl}$ and $\mathrm{CaSO}_{4}$

$m$ : molality

$n_{i}:$ number of moles of $i$ th salt in the solution

$S:$ total salts

\section{Literature}

1) D'Ans, J. : “Lösungsgleichgewichte der Systeme der Salze ozeanischer Salzablagerungen" (1933)

2) Fleming, Sverdrup and Johnson: "The Ocean, Their Physics, Chemistry and General Biology" p. 173 (1946)

3) Hara, Higashi and Nakamura : J. Chem. Sac. Japan, Ind. Chem. Sec., 34, 166 (1931)

4) Haugen, Watson and Ragatz: "Chemical Process Principles" (1954)

5) Ishibashi and Murakami : Bull. Soc. Salt Sci. Japan, 4, 51 (1950)

6) Kaganovich, Y. Y. : Doblady Akad, Nauk S. S. S. R. 87. 89 (1952)

7) Kaganovich, Y. Y.: Zhwr. Obshelei Khim., 21, 28 (1951)

8) Kusunoki, K. Chem. Eng. (Japan), 21, 775 (1957) 
9) "Seienyô Zuhyô Shû" Nippon Senbai Kosha Chûô Kenkyu Sho

10) Oka, S. : J. Electrochem. Soc, Japan, 25, 312 (1957)

11) Onodera and Tenmei : En Gijutsu Kenkyu, No. 8, 17 (1949)

12) Osako, Y.: "Kagaku-Jikken-Gaku, Dai-1-bu, Dai- $2-k a n "$ p. 207.

13) Rutzkov, A. P. : Zhur. Pirklad Khim. 21. 820 (1948)

14) Uchida and Ogawa : Bull. Soc. Salt Sci. Japan. 7. 149 (1953)

15) Uchida and Shiba: Bull. Soc. Salt Sci. Japan, 6, 51 (1952)

\section{Construction of Enthalpy-Composition Diagram for Manufacture of Common Salt from Sea Water}

\section{Kōichirō Kusunoki*}

The enthalpy-composition diagram, Fig. 1, has been constructed, with a view to facilitating the computation of heat balance in the manufacture of common sait. Although the method of construction adopted is substantially the same as that for ordinary binary system, special attention has been paid to the following points, because the sea water system is composed of many components as denoted in Table 1.

1. Expression of composition: From many experiments, it has been found that the relative proportion of various salts in the sea water is constant anywhere on earth. At any concentration stage, the salts in the sea water may be conveniently expressed in a mass as "total salts " $\mathrm{S}$, which includes salts both in the solution phase and the solid phase. Therefore, the sea water system may be denoted as a binary system of $\mathrm{S}$ and $\mathrm{H}_{2} \mathrm{O}$ as shown in Fig. 1 . The weight per cent of $\mathrm{S}$ has been calculated from the following equation :

$$
\text { Per cent of } S=\frac{(\text { weight of salts in soln. })+(\text { weight of deposited salts })}{\text { (weight of solution })+(\text { weight of deposited salts })} \times 100
$$

2. State of system : For the calculation of enthalpy, the state of system or the composition of the solution and deposit must be known. This state was estimated by M. Ishibashi ${ }^{5)}$ Fig. 2) and $Y$. Onodera ${ }^{11}$ ) from the experiments on isothermal concentration at 1 atm, and by $J$. D'Ans ${ }^{1)}$, from the researches in the solution equilibrium of ocean salts.

3. Enthalpy : The enthalpy of the system is given as follows:

$$
H=H_{l}+H_{\text {。 }}
$$

$H_{8}$ was obtained from the enthalpy of each deposited component.

$H_{\text {! }}$ was approximately evaluated by the following equation :

$$
H_{l}=n_{1} H_{1}+n_{2} H_{2}+\cdots \cdots \cdots \cdots
$$

where $n_{i}$ is a number of moles of component $i$ in the brine and $H_{i}$, the enthalpy of $i$ th single salt solution at the same molality as the total molality of the brine.

4. Lines of isabaric boiling point: The lines have been derived from the experiments by $\mathrm{S}$. Uchida ${ }^{14), 15)}$

From the above calculations and data, Fig. 1 has been obtained. Although not free from faults, this diagram, aided by the pressure table for saturated steam, would meet the purpose of making easy the calculation of heat balance in the concentration process.

* Department of Applied Chemistry. Kyushu University 